\title{
Factors that influence recurrent lumbar disc herniation
}

\author{
Mesut E Yaman *, Atilla Kazancı, Nur D Yaman, Ferhat Baş, Gıyas Ayberk
}

\section{A B S T R A C T}

Introduction: The most common cause of poor outcome following lumbar disc surgery is recurrent herniation. Recurrence has been noted in $5 \%$ to $15 \%$ of patients with surgically treated primary lumbar disc herniation. There have been many studies designed to determine the risk factors for recurrent lumbar disc herniation. In this study, we retrospectively analysed the influence of disc degeneration, endplate changes, surgical technique, and patient's clinical characteristics on recurrent lumbar disc herniation.

Methods: Patients who underwent primary singlelevel L4-L5 lumbar discectomy and who were reoperated on for recurrent L4-L5 disc herniation were retrospectively reviewed. All these operations were performed between August 2004 and September 2009 at the Neurosurgery Department of Ataturk Education and Research Hospital in Ankara, Turkey.

Results: During the study period, 126 patients were reviewed, with 101 patients underwent primary single-level L4-L5 lumbar discectomy and 25 patients were reoperated on for recurrent L4-L5 disc herniation. Preoperative higher intervertebral disc height $(\mathrm{P}<0.001)$ and higher body mass index $(\mathrm{P}=0.042)$ might be risk factors for recurrence. Modic endplate changes were statistically significantly recurrent group $(\mathrm{P}=0.032)$.

Conclusion: Our study suggests that patients who had recurrent lumbar disc herniation had preoperative higher disc height and higher body mass index. Modic endplate changes had a higher tendency for recurrence of lumbar disc herniation. Well-planned and well-conducted large-scale prospective cohort studies are needed to confirm this and enable convenient treatment modalities to prevent recurrent disc pathology.

\section{Hong Kong Med J 2017;23:258-63}

DOI: 10.12809/hkmj164852

\section{${ }^{1}$ ME Yaman *, MD \\ A Kazancl, MD \\ ${ }^{3}$ ND Yaman, MD \\ ${ }^{4} \mathrm{~F}$ Baş \\ ${ }^{2}$ G Ayberk, MD}

Department of Neurosurgery, Memorial Ankara Hospital, Ankara, Turkey

2 Department of Neurosurgery, Ataturk Education and Research Hospital, Ankara, Turkey

${ }^{3}$ Ankara University School of Medicine, Ankara, Turkey

${ }^{4}$ Hacettepe University Graduate School of Health Sciences, Ankara, Turkey

An earlier version of this paper was presented orally at the 15th World Congress of Neurosurgery held in Seoul, South Korea on 8-13 September 2013.

* Corresponding author: mesutemreyaman@hotmail.com

New knowledge added by this study

- Preoperative higher disc height, higher body mass index, and greater Modic endplate changes are important factors in recurrent lumbar disc herniation.

Implications for clinical practice or policy

- This study revealed that patients who had lumbar disc herniation with preoperative higher disc height and Modic changes have a higher tendency to recurrence of lumbar disc herniation.

- It is important to bear these factors in mind preoperatively and ensure discussion of expectations of surgery with the patient.

\section{Introduction}

Single-level lumbar discectomy is a very common surgical procedure and has been proven to be beneficial for patients with lumbar disc herniation (LDH). Recurrent lumbar disc herniation (rLDH) is defined as disc herniation at the same level, regardless of ipsilateral or contralateral herniation, in a patient who has experienced a pain-free interval of at least 6 months after surgery. ${ }^{1,2}$ The true incidence of same-level rLDH after lumbar discectomy is unclear.
The recurrence rate of $\mathrm{LDH}$ has been reported to be $5 \%$ to $15 \% .^{1-5}$ There have been many studies designed to determine the recurrence of $\mathrm{LDH}$, and various risk factors suggested including disc degeneration, trauma, age, smoking, gender, and obesity. ${ }^{1,3,6}$ Radiologically identifiable factors, such as disc degeneration, disc height, and sagittal range of motion have been shown to be related to spinal instability and consequently to $\mathrm{rLDH}^{7-9}$ In this retrospective study, we analysed the influence of disc 
degeneration, endplate changes, surgical technique, and patient's clinical characteristics on rLDH.

\section{Methods}

We examined factors that could influence the recurrence of $\mathrm{LDH}$, especially in those with the highest recurrence rate, and to minimise the biomechanical changes at every level. We retrospectively reviewed the medical records of patients with L4-L5 LDH who underwent lumbar discectomy between August 2004 and September 2009 at the Neurosurgery Department of Ataturk Education and Research Hospital in Ankara, Turkey. This hospital is a tertiary referral hospital and a centre for education and scientific research. This study was approved by the Ethics Committee of Ankara Ataturk Education and Research Hospital, Turkey. The principles outlined in the Declaration of Helsinki have also been followed.

Patients were excluded if they had any of the following: prior lumbar surgery at another institution, segmental instability, vertebral fractures and spinal infections, other types of degenerative disc disease, tumours, pregnancy, and age over 75 years. Patients were included if they had radicular pain for at least 3 months that was refractory to 6 weeks of conservative treatment with or without neurological deficit, numbness in the lumbar spine, buttock, and/ or lower extremity, age between 21 and 75 years, and magnetic resonance imaging (MRI) and/or computed tomography demonstrating anatomical unilateral LDH correlating with symptoms. In the rLDH group, patients were additionally required to have had a pain-free interval of at least 6 months following the first surgery. We compared the patients' demographic and clinical characteristics (age, sex, body mass index [BMI], diabetes mellitus, smoking, herniation type), preoperative radiological parameters (Pfirrmann disc degeneration grade, Modic endplate changes, disc height), surgical technique (microdiscectomy, open discectomy), and duration of symptoms. All surgeries were performed by the same group of surgeons via microdiscectomy or open discectomy technique as previously reported and standardised by Williams ${ }^{10}$ and Mixter. ${ }^{11}$ The type of herniation was classified as protrusion, extrusion, or sequestration after retrospective review of surgical records and MRI studies. The staff in the radiological department were blinded to the outcome of the study. Lumbar MRI and simple radiographic examinations were performed in all patients before surgery. Intervertebral disc height measurements were calculated using the lateral radiographs. The degree of disc degeneration was assessed on T2weighted sagittal MRI sequences. Disc degeneration was classified by our radiological department in a retrospective and blinded manner according to modified Pfirrmann criteria as shown in Table $1 .^{12}$

\section{復發性腰椎間盤突出症的影響因素}

\section{Mesut E Yaman, Atilla Kazancı, Nur D Yaman, Ferhat Baş,} Giyas Ayberk

引言：復發性腰椎間盤突出症是腰椎間盤手術治療效果不佳的最常見 原因。5\%至 $15 \%$ 接受手術治療的患者會出現復發。文獻中記錄許多 有關復發性腰椎間盤突出症影響因素的研究。我們回顧分析椎間盤退 變、終板變化、外科技術和患者臨床特徵對復發性腰椎間盤突出的影 響。

方法：回顧分析於 2004 年 8 月至 2009 年 9 月期間在土耳其安卡拉的 Ataturk Education and Research Hospital神經外科部門進行L4-L5原 發性以及復發性腰椎間盤切除術的患者。

結果：研究期間共有 126 例進行有關手術, 其中 101 例為原發性, 另 25 例為復發性。有高術前椎間盤高度 $(\mathrm{P}<0.001)$ 和高質量指數 $(P=0.042)$ 可能是復發的危險因素。復發組的終板Modic變化高於 原發組, 並達統計上的顯著性 $(\mathrm{P}=0.032)$

結論：本研究結果顯示復發性腰椎間盤突出症患者比原發性患者有較 高的術前椎間盤高度及質量指數。復發性患者有較大傾向有較大的腰 終板Modic變化。須進一步進行有詳盡完備設計、大規模的前瞻性隊 列研究以確認本研究的結果, 進而找出合宜的治療方案來防止復發性 椎間盤病變的出現

Modic endplate changes were also classified with the help of our radiological department on T1/T2weighted sagittal MRI sequences, again blinded to the outcome. ${ }^{13,14}$

Data analysis was performed using the Statistical Package for the Social Sciences (Windows version 11.5; SPSS Inc, Chicago [IL], United States). Test of normality was applied to parametric data. Parametric numerical data were compared with Student's $t$ test and non-parametric data with Mann-Whitney $U$ test. Chi squared test was used with Fisher's exact test to compare categorical and nominal variables as appropriate. Wilcoxon signedrank test was used to compare differences between paired data. To identify the associations between recurrence and diabetes mellitus and smoking, logistic regression analysis was used. In detail, recurrence was included in the regression model as a dependent variable; smoking status and existence of diabetes mellitus were included as covariants and the enter mode was used. P value was used to determine whether the differences were statistically significant. A P value of $<0.05$ was considered statistically significant.

\section{Results}

A retrospective analysis of 600 patients who underwent surgery between August 2004 and September 2009 for only a single-level LDH was performed. The level of disc herniation was L1-L2 in four (0.7\%), L2-L3 in 17 (2.8\%), L3-L4 in 39 (6.5\%), L4-L5 in 289 (48.2\%), and L5-S1 in 251 (41.8\%) 
patients. Of the 600 patients, 44 had $\mathrm{rLDH}$; their recurrent group. Patients in the recurrent group respective distributions of disc levels were 0,1 , were pain-free for at least 6 months after the first 3 , 25, and 15 . The total recurrence rate was $7.3 \%$. operation with a median of 240 days (range, 188Recurrence rate for L4-L5 level was the highest at 1260 days).

$8.6 \%$. The mean follow-up time of all patients was

After applying the exclusion/inclusion 323 days. The mean symptom duration was 78 days criteria, we retrospectively analysed 126 patients for the non-recurrent group and 77 days for the who underwent primary single-level L4-L5 lumbar

TABLE I. Pfirrmann disc degeneration grade ${ }^{12}$

\begin{tabular}{lllll}
\hline Type & Structure & Nucleus & Signal intensity & Disc height \\
\hline I & Homogeneous & Light & Hyperintense & Normal \\
II & Heterogeneous with horizontal line & Light & Hyperintense & Normal \\
III & Heterogeneous, grey & Dark & Intermediate & Normal \\
IVA & Heterogeneous, grey & Dark & Intermediate & Reduced \\
IVB & Heterogeneous, black & Lost & Hypointense & Reduced \\
V & Heterogeneous, black & Lost & Hypointense & Collapsed \\
\hline
\end{tabular}

TABLE 2. Univariate analysis of demographics, and clinical and radiological characteristics in the non-recurrent group and the recurrent group before the first surgery

\begin{tabular}{|c|c|c|c|}
\hline \multirow[t]{2}{*}{ Variable } & \multicolumn{2}{|c|}{ Mean \pm standard deviation or No. (\%) of patients } & \multirow[t]{2}{*}{$P$ value } \\
\hline & Recurrent group ( $n=25)$ & Non-recurrent group $(n=101)$ & \\
\hline Age (years) & $53.2 \pm 12.3$ & $47.9 \pm 12.2$ & $0.055^{\star}$ \\
\hline $\operatorname{Sex}(M / F)$ & 17 (68.0) / 8 (32.0) & 70 (69.3) / 31 (30.7) & $0.899 \dagger$ \\
\hline Body mass index $\left(\mathrm{kg} / \mathrm{m}^{2}\right)$ & $24.8 \pm 0.8$ & $23.8 \pm 1.3$ & $0.042^{*}$ \\
\hline Diabetes mellitus & & & $0.164 \dagger$ \\
\hline Positive & $5(20.0)$ & $10(9.9)$ & \\
\hline Negative & $20(80.0)$ & $91(90.1)$ & \\
\hline Smoking & & & $0.349 \dagger$ \\
\hline Smoker & $13(52.0)$ & $42(41.6)$ & \\
\hline Non-smoker & $12(48.0)$ & $59(58.4)$ & \\
\hline Herniation type & & & $0.057 \ddagger$ \\
\hline Protrusion & $9(36.0)$ & $58(57.4)$ & \\
\hline Sequestration & $2(8.0)$ & $6(5.9)$ & \\
\hline Extrusion & $14(56.0)$ & $37(36.6)$ & \\
\hline Disc degeneration grade (Pfirrmann) & & & $0.079 \dagger$ \\
\hline II-III & $11(44.0)$ & $64(63.4)$ & \\
\hline IV $(A+B)$ & $14(56.0)$ & $37(36.6)$ & \\
\hline Endplate changes (Modic) & & & $0.032 \ddagger$ \\
\hline 0 & $7(28.0)$ & $51(50.5)$ & \\
\hline 1 & $4(16.0)$ & $8(7.9)$ & \\
\hline 2 & $11(44.0)$ & $42(41.6)$ & \\
\hline 3 & $3(12.0)$ & 0 & \\
\hline Disc height (mm) & $19.1 \pm 4.6$ & $15.0 \pm 3.3$ & $<0.001^{\star}$ \\
\hline Type of surgery & & & $0.602 \dagger$ \\
\hline Open surgery & $17(68.0)$ & $63(62.4)$ & \\
\hline Microdiscectomy & $8(32.0)$ & $38(37.6)$ & \\
\hline Symptom duration (days) & $77.6 \pm 101.2$ & $78.8 \pm 110.9$ & $0.978^{*}$ \\
\hline
\end{tabular}


discectomy and who were reoperated on for $\mathrm{rLDH}$. The patients were divided into recurrent $(n=25)$ and non-recurrent $(\mathrm{n}=101)$ group (Fig).

Univariate analysis for demographics, and clinical and radiological characteristics of the recurrent and non-recurrent groups is shown in Table 2. There were no significant differences in the age, sex, type of disc herniation, type of surgery, and duration of symptoms between the two groups. Of the patients, $13(52.0 \%)$ in the recurrent group and $42(41.6 \%)$ in the non-recurrent group were smokers. In comparison with non-smokers, smokers had a $50 \%$ higher recurrence rate (odds ratio $[\mathrm{OR}]=1.52$; 95\% confidence interval [CI], 0.63-3.66). Five (20.0\%) patients in the recurrent group and 10 (9.9\%) in the non-recurrent group had diabetes mellitus. Patients with diabetes mellitus had twice the recurrence rate of those without (OR=2.27; 95\% CI, 0.70-7.38). Preoperative mean intervertebral disc heights were significantly different between the recurrent $(19.1 \mathrm{~mm})$ and non-recurrent $(15.0 \mathrm{~mm})$ groups $(\mathrm{P}<0.001)$. A higher preoperative intervertebral disc space might be a risk factor for recurrence. A higher BMI was a statistically significant factor in the recurrent group $(\mathrm{P}=0.042)$. Modic endplate changes were statistically higher in the recurrent group than in the non-recurrent group $(\mathrm{P}=0.032)$. In the nonrecurrent group, $13(12.9 \%)$ patients showed grade II, 51 (50.5\%) showed grade III, 24 (23.8\%) showed grade IVA, and $13(12.9 \%)$ showed grade IVB Pfirrmann disc degeneration. Although Pfirrmann disc degeneration was not statistically significant between the two groups $(\mathrm{P}=0.079)$, it might still be a moderate marker for a potential risk of recurrence.

The comparative analysis of preoperative clinical and radiological characteristics of the recurrent group is shown in Table 3. Before the first surgery, one (4\%) patient showed grade II, 10 (40\%) showed grade III, eight (32\%) showed grade IVA, and six (24\%) showed grade IVB Pfirrmann disc degeneration. In one patient, grade II Pfirrmann degeneration progressed to IVA before the second

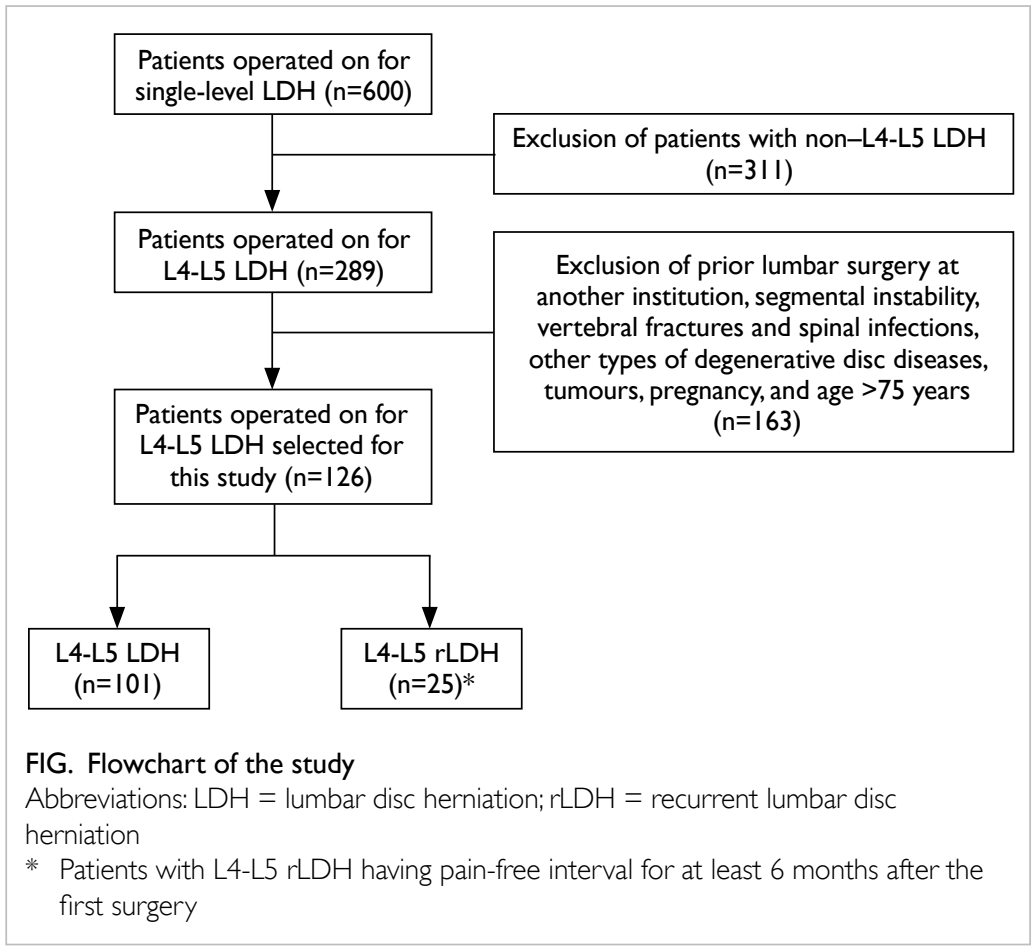

TABLE 3. Comparison of preoperative clinical and radiological characteristics of the recurrent patients $(n=25)^{*}$

\begin{tabular}{|c|c|c|c|}
\hline Characteristic & Initial surgery & Second surgery & $P$ value \\
\hline Herniation type & & & $0.320 \dagger$ \\
\hline Protrusion & $9(36)$ & $7(28)$ & \\
\hline Sequestration & $2(8)$ & 0 & \\
\hline Extrusion & $14(56)$ & $18(72)$ & \\
\hline Disc degeneration (Pfirrmann) & & & $0.072 \ddagger$ \\
\hline II-III & $11(44)$ & $5(20)$ & \\
\hline IV $(A+B)$ & $14(56)$ & $20(80)$ & \\
\hline Endplate changes (Modic) & & & $0.821 \dagger$ \\
\hline 0 & $7(28)$ & $5(20)$ & \\
\hline 1 & $4(16)$ & $6(24)$ & \\
\hline 2 & $11(44)$ & $11(44)$ & \\
\hline 3 & $3(12)$ & $3(12)$ & \\
\hline Disc height $(\mathrm{mm})$ & $19.1 \pm 4.6$ & $18.1 \pm 4.4$ & $0.201 \S$ \\
\hline Body mass index $\left(\mathrm{kg} / \mathrm{m}^{2}\right)$ & $24.8 \pm 0.8$ & $25.5 \pm 0.9$ & $0.020 \S$ \\
\hline Median (range) pain-free interval (days) & - & $240(188-1260)$ & $0.020 \S$ \\
\hline $\begin{array}{l}* \text { Data are shown as No. (\%) of patients, ur } \\
\dagger \text { Fisher's exact test } \\
\ddagger \text { Chi squared test } \\
\S \text { Wilcoxon signed-rank test }\end{array}$ & wise specified & & \\
\hline
\end{tabular}


surgery. Six of 10 patients with grade III changed to IVB, three changed to IVA, and one remained unchanged with a Pfirrmann degeneration grade III after recurrence.

These results led us to consider the relationship between grade of degenerated disc and herniation type. Herniation type was compared with Pfirrmann disc degeneration degree and Modic endplate changes. Patients with extrusion-sequestration herniation had a statistically significant higher Pfirrmann disc degeneration in contrast to patients with protrusions $(\mathrm{P}=0.016)$. Nonetheless, there was no correlation between Modic changes and herniation type $(\mathrm{P}=0.279)$.

\section{Discussion}

Degenerative disc disease remains a poorly understood phenomenon because of the lack of precise definitions for healthy and degenerated discs. Decreased nutrition is the final common pathway for degenerative disc disease and the status of the endplate plays a crucial role in controlling the extent of diffusion and is the only source of nutrition. ${ }^{15} \mathrm{~A}$ recurrence rate of $5 \%$ to $15 \%$ for LDH has been reported..$^{1-5}$ Differentiation of recurrent disc herniation from scar formation will allow for improved treatment choices and selection of patients who may benefit from a second surgery. Gadoliniumenhanced MRI is thought to be the best modality to differentiate between these two diagnoses. There is much debate about the risk factors for rLDH and it is very difficult to define them because many clinical and complicated biomechanical parameters are involved.

In this study, we analysed the influence of disc degeneration, endplate changes, surgical technique, and patient's clinical characteristics (age, gender, BMI, symptom duration, herniation type, smoking status, and diabetes). Kim et $\mathrm{al}^{6}$ reported old age, high BMI, protrusion type of disc herniation, and positive Modic changes as risk factors after percutaneous endoscopic discectomy. Swartz and Trost ${ }^{2}$ however, found that age, gender, smoking status, level of herniation, and duration of symptoms were not associated with $\mathrm{rLDH}$. We showed that disc height, BMI, and Modic endplate changes were significantly correlated with a higher incidence of rLDH. Although diabetes and smoking were not statistically significant in our study, patients with diabetes had twice the recurrence rate of those without. Furthermore, patients who were a smoker had a $50 \%$ higher recurrence rate in contrast to nonsmokers. The exact mechanism by which smoking contributes to disc degeneration is incompletely understood, but may be related to disc annulus nutrition and oxygenation, as well as increases in intradiscal pressure due to excessive coughing. Vascular insufficiency as a result of atheromas should also be considered. ${ }^{16-20}$ Analogous with our results, these presumptions may account for smoking as a cause of rLDH. In contrast with these findings, however, some studies found no relationship between smoking and $\mathrm{rLDH}{ }^{21-23}$

Clinical studies of disc height and recurrence have shown that degenerative segments with preserved disc height have a latent instability compared with segments with collapsed discs. ${ }^{8}$ Other studies have shown that the restabilisation stage begins when disc height is reduced by $50 \%{ }^{7}$ Similar to these studies, our study showed that preoperative higher intervertebral disc space measurements were significantly more important in recurrence $(\mathrm{P}<0.001)$.

Pfirrmann disc degeneration grade was not statistically significant in the recurrent group in contrast to non-recurrent group $(\mathrm{P}=0.079)$, but patients with extrusion and sequestration had a statistically significant higher Pfirrmann disc degeneration than patients with protrusions $(\mathrm{P}=0.016)$. These findings provide evidence that the healing processes that occur in the outer lamellas after annular injury may not be sufficient for effective reconstitution of the external annulus in degenerated discs..$^{24,25}$ Increases in disc degeneration cause larger volumes of herniation type. Studies of Modic endplate changes after lumbar discectomy have shown incremental changes in disc degeneration grade. ${ }^{18,26}$ It is accepted that Modic type 1 changes are dynamically unstable and inflammatory lesions, whereas type 2 lesions are much more stable and unchangeable. ${ }^{26}$ Therefore, posterior lumbar interbody fusion combined with pedicle screw fixation is suggested for degenerative lumbar disc disease with Modic changes. ${ }^{27}$ Another study suggested treatment of Modic type 1 and 2 lesions with degenerative disc disease with posterior dynamic stabilisation..$^{28}$ Our study showed that Modic changes were statistically higher in the recurrent group than the non-recurrent group $(\mathrm{P}=0.032)$. These findings suggest that patients with LDH and higher preoperative disc heights and Modic changes have a higher risk and tendency to recurrence of LDH. Although our study does not include different modalities to include lumbar disc diseases with Modic changes, the results might suggest a supplemental approach such as posterior stabilisation and fusion, or newly proposed treatment options with dynamic posterior stabilisation.

This study has several limitations. It would have a greater impact if we had included a larger subgroup population, especially for rLDH. To investigate factors that influence recurrence of L4-L5 disc herniation, however, several clinical and radiological parameters such as canal diameter, facet angle, annular defect size, location of the herniation type etc would need to be considered. The aim of this study was to focus 
on the effect of disc height, endplate changes, and disc degeneration in rLDH at L4-L5 level. As only univariate analyses were performed, we have no adjustment for potential confounding, hence the independent effects of the risk factors could not be documented. A prospective study would obtain more precise results, especially due to standardised sampling and classification of data.

\section{Conclusion}

This study suggests that patients who had LDH with higher preoperative disc height, higher BMI, and Modic endplate changes have a higher tendency for rLDH. Well-planned and well-conducted large-scale prospective cohort studies are essential to firmly evaluate and determine factors involved in rLDH.

\section{Acknowledgement}

We thank Ms Fatma Kubra Erbay from Department of Micro and Nanotechnology, TOBB University of Economics and Technology, Ankara, Turkey for her great effort in revising the statistical results of this study.

\section{Declaration}

All authors have disclosed no conflicts of interest.

\section{References}

1. Suk KS, Lee HM, Moon SH, Kimm NH. Recurrent lumbar disc herniation: results of operative management. Spine (Phila Pa 1976) 2001;26:672-6.

2. Swartz KR, Trost GR. Recurrent lumbar disc herniation. Neurosurg Focus 2003;15:E10.

3. Connolly ES. Surgery for recurrent lumbar disc herniation. Clin Neurosurg 1992;39:211-6.

4. Fandiño J, Botana C, Viladrich A, Gomez-Bueno J. Reoperation after lumbar disc surgery: results in 130 cases. Acta Neurochir (Wien) 1993;122:102-4.

5. Mobbs RJ, Newcombe RL, Chandran KN. Lumbar discectomy and the diabetic patient: incidence and outcome. J Clin Neurosci 2001;8:10-3.

6. Kim JM, Lee SH, Ahn Y, Yoon DH, Lee CD, Lim ST. Recurrence after successful percutaneous endoscopic lumbar discectomy. Minim Invasive Neurosurg 2007;50:82-5.

7. Axelsson P, Karlsson BS. Intervertebral mobility in the progressive degenerative process. A radiostereometric analysis. Eur Spine J 2004;13:567-72.

8. Hasegawa K, Kitahara K, Hara T, Takano K, Shimoda H, Homma T. Evaluation of lumbar segmental instability in degenerative diseases by using a new intraoperative measurement system. J Neurosurg Spine 2008;8:255-62.

9. Zhao F, Pollintine P, Hole BD, Dolan P, Adams MA. Discogenic origins of spinal instability. Spine (Phila $\mathrm{Pa}$ 1976) 2005;30:2621-30.

10. Williams RW. Microlumbar discectomy: a conservative surgical approach to the virgin herniated lumbar disc. Spine (Phila Pa 1976) 1978;3:175-82.

11. Mixter WJ. Pitfalls in the surgery of the ruptured intervertebral disk. J Fla Med Assoc 1952;39:159-67.
12. Pfirrmann CW, Metzdorf A, Zanetti M, Hodler J, Boos N. Magnetic resonance classification of lumbar intervertebral disc degeneration. Spine (Phila Pa 1976) 2001;26:1873-8.

13. Modic MT, Masaryk TJ, Ross JS, Carter JR. Imaging of degenerative disk disease. Radiology 1998;168:177-86.

14. Modic MT, Steinberg PM, Ross JS, Masaryk TJ, Carter JR. Degenerative disk disease: assessment of changes in vertebral body marrow with MR imaging. Radiology 1988;166(1 Pt 1):193-9.

15. Rajasekaran S, Venkatadass K, Naresh Babu J, Ganesh K, Shetty AP. Pharmacological enhancement of disc diffusion and differentiation of healthy, ageing and degenerated discs: results from in-vivo serial post-contrast MRI studies in 365 human lumbar discs. Eur Spine J 2008;17:626-43.

16. Akmal M, Kesani A, Anand B, Singh A, Wiseman M, Goodship A. Effect of nicotine on spinal disc cells: a cellular mechanism for disc degeneration. Spine (Phila Pa 1976) 2004;29:568-75.

17. Frymoyer JW, Pope MH, Costanza MC, Rosen JC, Goggin JE, Wilder DG. Epidemiologic studies of low-back pain. Spine (Phila Pa 1976) 1980;5:419-23.

18. Iwahashi M, Matsuzaki H, Tokuhashi Y, Wakabayashi K, Uematsu Y. Mechanism of intervertebral disc degeneration caused by nicotine in rabbits to explicate intervertebral disc disorders caused by smoking. Spine (Phila Pa 1976) 2002;27:1396-401.

19. Nemoto Y, Matsuzaki H, Tokuhasi Y, et al. Histological changes in intervertebral discs after smoking cessation: experimental study using a rat passive smoking model. J Orthop Sci 2006;11:191-7.

20. Stairmand JW, Holm S, Urban JP. Factors influencing oxygen concentration gradients in the intervertebral disc. A theoretical analysis. Spine (Phila Pa 1976) 1991;16:444-9.

21. Kara B, Tulum Z, Acar U. Functional results and the risk factors of reoperations after lumbar disc surgery. Eur Spine J 2005;14:43-8.

22. Meredith DS, Huang RC, Nguyen J, Lyman S. Obesity increases the risk of recurrent herniated nucleus pulposus after lumbar microdiscectomy. Spine J 2010;10:575-80.

23. Palma L, Carangelo B, Muzii VF, Mariottini A, Zalaffi A, Capitani S. Microsurgery for recurrent lumbar disk herniation at the same level and side: do patients fare worse? Experience with 95 consecutive cases. Surg Neurol 2008;70:619-21.

24. Hampton D, Laros G, McCarron R, Franks D. Healing potential of the anulus fibrosus. Spine (Phila Pa 1976) 1989;14:398-401.

25. Osti OL, Vernon-Roberts B, Fraser RD. 1990 Volvo Award in experimental studies. Anulus tears and intervertebral disc degeneration. An experimental study using an animal model. Spine (Phila Pa 1976) 1990;15:762-7.

26. Rahme R, Moussa R, Bou-Nassif R, et al. What happens to Modic changes following lumbar discectomy? Analysis of a cohort of 41 patients with a 3- to 5 -year follow-up period. J Neurosurg Spine 2010;13:562-7.

27. Kwon YM, Chin DK, Jin BH, Kim KS, Cho YE, Kuh SU. Long term efficacy of posterior lumbar interbody fusion with standard cages alone in lumbar disc diseases combined with modic changes. J Korean Neurosurg Soc 2009;46:322-7.

28. Öktenoglu T, Ozer AF, Sasani M, et al. Posterior dynamic stabilization in the treatment of lumbar degenerative disc disease: 2-year follow-up. Minim Invasive Neurosurg 2010;53:112-6. 